\title{
Regime Shifting in the International Intellectual Property System
}

\author{
Laurence R. Helfer
}

\begin{abstract}
The international intellectual property system provides an important illustration of how regime complexity shapes domestic and international strategies of states and non-state actors. This article describes and graphically illustrates the multifaceted nature of the international intellectual property system. It then analyzes the consequences of regime complexity for international and domestic politics, emphasizing the strategy of regime shifting and its consequences for chessboard politics and the domestic implementation of international rules.
\end{abstract}

\rceil he institutions and rules of the international intellectual property system provide an important illustration of how regime complexity shapes domestic and international politics. In particular, complexity enables a strategy of "regime shifting" whereby states and nonstate actors relocate rulemaking processes to international venues whose mandates and priorities favor their concerns and interests. Forum shopping, described in several other contributions to this symposium, also involves a change of venues. But the goal is usually a single favorable decision. Regime shifting, by contrast, is an iterative, longerterm strategy that seeks to create outcomes that have feedback effects in other venues. Regime shifting works by broadening the policy spaces within which relevant decisions are made and rules are adopted, thereby expanding the constellation of interests and issues that actors must consider when defining rules, norms, and decision-making procedures.

\section{The Origins of Complexity in the International Intellectual Property System}

The international intellectual property system is composed of a dense thicket of linkages and relationships among treaties, international organizations, and multilateral, regional and bilateral negotiating venues. Deeply nested multilateral treaties comprise some parts of this system,

Laurence R. Helfer is Professor of Law and Director, International Legal Studies Program, Vanderbilt University Law School (larry.helfer@vanderbilt.edu). Thanks to Karen Alter, Sophie Meunier, David Dana, and the other participants in this symposium for their helpful comments and suggestions. the most famous being the Agreement on Trade-Related Aspects of Intellectual Property Rights (TRIPs). TRIPs is a member of the family of World Trade Organization (WTO) treaties and itself incorporates an earlier group of multilateral treaties (including the Berne Convention, the Paris Convention, and the Rome Convention) protecting patents, trademarks, copyrights, and other intellectual property rights. Rules relating to intellectual property also exist in other international institutions, such as the Conference of the Parties to the Convention on Biological Diversity (CBD), the World Health Organization (WHO), the World Intellectual Property Organization (WIPO), and the Food and Agriculture Organization (FAO). Parallel treaties and institutions predominate in other areas, such as the intersection of human rights and intellectual property, a topic that has been actively studied from different perspectives within the United Nations human rights system as well as the WTO and WIPO. ${ }^{1}$

The international intellectual property system was not always so densely populated. As recently as the early 1990s, the treaties and international organizations concerned with intellectual property occupied a highly specialized and technocratic corner of international law with few connections to other issue areas. That relative isolation ended in 1994 when the United States and the European Communities, pressured by their respective intellectual property industries, shifted negotiations over intellectual property from the WIPO to the WTO and linked the result of those negotiations (the TRIPs Agreement) to the new WTO dispute settlement system. Any nation seeking to join the international trade club was required to accept a package deal that included both strong intellectual property rights and robust international enforcement of those rights. ${ }^{2}$

That TRIPs dramatically expanded intellectual property protection standards is well known to legal scholars 
Figure 1

The international intellectual property system

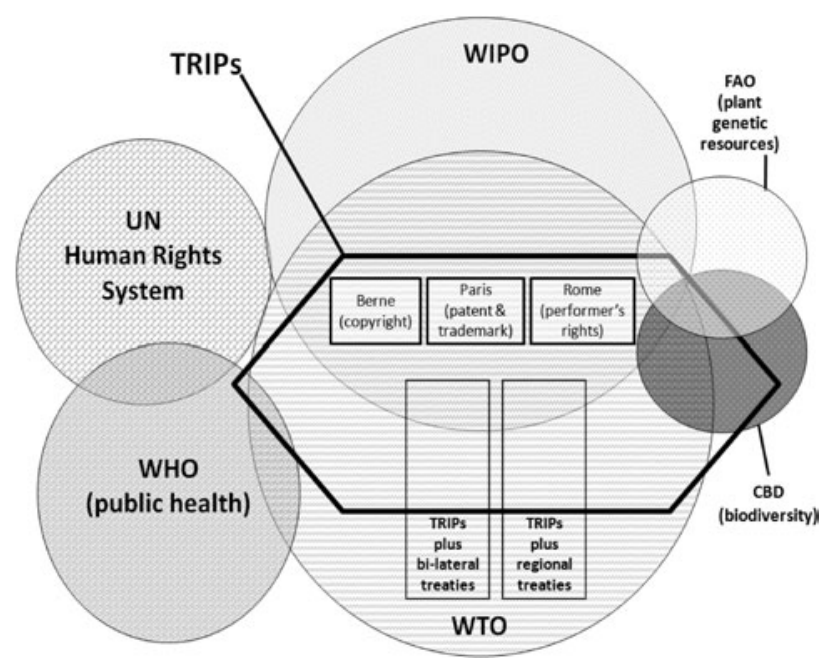

and political scientists. ${ }^{3}$ What is less understood is how TRIPs created tension points in other issue areas — such as human rights, public health, biodiversity, and plant genetic resources - that acted as catalysts for new intellectual property rules in nested, parallel, and overlapping international institutions. These tension points had both substantive and procedural dimensions. ${ }^{4}$

Substantively, TRIPs required states to grant intellectual property rights in fields - such as genetic resources, pharmaceuticals, and plant varieties-that developing countries believed should not be treated as private property on moral or cultural grounds. The conflicts between TRIPs and this competing regulatory approach weakened the clarity of existing legal rules and created uncertainty for states over how to reconcile the resulting conflicts.

Procedurally, tensions were created by TRIPs' more stringent enforcement mechanisms as compared to the weaker enforcement structures that exist in international regimes outside of the WTO. As a treaty nested within the WTO, compliance with TRIPs is achieved through the WTO dispute settlement system, a system in which ac hoc panels and the WTO Appellate Body issue rulings that interpret IP protection rules and in which states that fail to comply with these rulings risk retaliatory trade sanctions. The strength of the WTO dispute settlement system created a structural imbalance whereby the stronger pressures to adhere to TRIPs undermined states' ability to comply with the rules of other regimes where those rules intersected with TRIPs.

\section{The Consequences of Complexity in the International Intellectual Property System}

TRIPs' expansion of intellectual property protection rules and enforcement mechanisms engendered resistance from developing countries and civil society groups. Although developing countries had accepted TRIPs as the price of admission to the WTO, many had done so without giving adequate consideration to the treaty's costs or its domestic political consequences. Civil society groups feared that TRIPs would undermine the rules and objectives of the human rights, public health, biodiversity, and plant genetic resources regimes in which they carried out their advocacy work. $^{5}$

In the decade following the adoption of TRIPs, both sets of actors worked to limit the adverse effects of the treaty and to roll back its more onerous provisions. In response to these efforts, industrialized countries (most notably the United States and the European Communities) and their intellectual property industries attempted to shore up support for TRIPs and to extend its provisions by adding them to regional and bilateral trade and investment treaties. These competing efforts to undermine and extend TRIPs where characterized by at least three of the five mechanisms described by Alter and Meunier in their introductory article. ${ }^{6}$

First, state and nonstate actors adopted a strategy of "regime shifting." As I will explain, regime shifting enabled both powerful and weaker states and their allies to relocate rulemaking initiatives to international venues concerned with other issue areas — such as foreign investment, human rights, public health, and biodiversity. These regimes were more closely aligned with the shifters' interests because of their distinctive institutional mandates, differing memberships, or greater permeability to non-state actors.

Second, the expansion of the intellectual property system privileged certain strategies, arguments, and outcomes while disfavoring others - a quintessential illustration of chessboard politics. These politics are masked if one takes a static snapshot of the system at a single moment. Observers must instead adopt a dynamic perspective that considers the development of the system over time, including the interactive effects of simultaneous and sequential negotiations in multiple venues. Examining how intellectual property rules developed across international institutions reveals a principal objective of regime shifting - the creation of legal rules in one forum as an intermediate strategy for later incorporating those rules into other institutions and treaties. By adopting this multi-step strategy, actors can increase their bargaining position relative to the power they could have exercised were treaty-making confined to a single international venue.

Third and finally, complexity both shapes and constrains implementation politics, in particular how states incorporate international intellectual property rules into national legal systems. In some instances, complexity provides states with "cover" to implement their preferred interpretation of ambiguous treaty obligations. In others, it enables powerful countries to outflank weaker states by creating rules in one venue that eliminate or dramatically 
constrain the discretion those countries had previously negotiated in a different venue.

In the sections that follow, I elaborate on each of these three mechanisms.

\section{Regime Shifting by Powerful and Weaker States}

In the years immediately following the adoption of the TRIPs Agreement, industrialized countries whose domestic industries benefitted from strong intellectual property rights sought to build on TRIPs by further expanding those rights. They initially turned to WTO and WIPO, organizations these states believed would be hospitable venues in which to negotiate new multilateral agreements. These efforts made some limited progress, but were quickly sidelined by more pressing problems, such as the failed attempt to launch a new round of trade talks in Seattle in 1999. Part of the backlash against the WTO was triggered by a growing resistance from developing countries and civil society groups to the moral, political, and economic legitimacy of TRIPs and the high costs of complying with the treaty. ${ }^{7}$

With negotiations in the WTO effectively stalled, both proponents and opponents of stronger intellectual property rules groups of states sought out greener pastures in other international regimes. Developing countries decamped to the $\mathrm{WHO}, \mathrm{FAO}$, and CBD. These organizations and negotiating venues offered these states advantages that they did not possess in the WTO and in WIPO. First, the goals of these institutions - to promote public health, plant genetic sources, and biodiversity - predisposed them to view challenges to expansive intellectual property rights sympathetically. Second, industrialized nations were either absent from these venues (the United States has never ratified the CBD, for example) or were represented by government ministries whose negotiating objectives were more sympathetic to developing country concerns. Third and finally, the WHO, $\mathrm{FAO}$, and $\mathrm{CBD}$, unlike the WTO, were relatively open to civil society, including NGOs that were highly critical of TRIPs and that worked with developing states to fashion strategies for challenging the treaty. ${ }^{8}$

The United States and the European Communities, by contrast, shifted their efforts from the WTO and WIPO to bilateral and regional trade and investment treaties, incorporating IP protection rules into these agreements. Industrialized states could more easily leverage their economic and political clout in these intimate negotiating forums. In exchange for enhanced access to their markets, these states demanded that developing countries ratify the new WIPO treaties or adhere to intellectual property protection standards that exceeded those found in TRIPs. Opponents derisively labeled these bilateral and regional agreements as "TRIPs plus" treaties."

The contemporaneous negotiation of competing intellectual property standards in different multilateral, regional, and bilateral venues created dense "policy spaces" in which legal rules intersected in complex and contradictory ways. ${ }^{10}$ For developing countries, the different goals, memberships, and NGO permeability of the WHO, FAO, and CBD provided opportunities to generate "counterregime norms" - treaties and nonbinding recommendations that challenged TRIPs. ${ }^{11}$ But even as counterregime norms were being created in these multilateral venues, they were undermined by the simultaneous negotiation of more stringent intellectual property rules in bilateral and regional "TRIPs plus" treaties.

Regime shifting also produced more convoluted and conflicting legal rules than would have been generated by a single international organization in which the same actors operated under a common subject-matter mandate. Not surprisingly, post-TRIPs scholarship analyzing the international intellectual property system has devoted considerable attention to reconciling the conflicting legal obligations. ${ }^{12}$

As this discussion illustrates, regime shifting in the international intellectual property system enabled both powerful and weaker states to develop legal rules that more accurately reflected their respective interests and concerns. As explained below, the goal of this strategy was not simply to create conflicting rules. Rather, regime shifting enabled these competing groups of countries to create new approaches that expanded the constellation of interests and issues that actors were required to consider when defining rules, norms, and decision-making procedures. The result was a substantial restructuring of the international intellectual property protection system.

\section{Chessboard Politics and the Consequences of Shifting Negotiating to Multiple International Venues}

A recognition that intellectual property protection standards are fashioned in multiple international regimes does not explain how states benefited from this disaggregated rulemaking venues. In fact, the inconsistent legal rules generated by regime shifting may initially appear detrimental to states' interests. As Alter and Meunier argue, however, chessboard politics cannot be discerned by examining a single historical moment. Rather, the strategies of actors and their consequences emerge over time as a result of the interactive effects of negotiating in multiple venues. Analyzing international regimes using this evolutionary perspective reveals the strategic advantages that complexity created for certain actors, in particular for less powerful states.

Recall that developing countries and civil society groups opposed to strong intellectual property rights shifted to other international regimes to create counterregime norms that conflicted with TRIPs and "TRIPs plus" agreements. To mount an effective challenge to these treaties, however, developing countries needed to do more than simply create counterregime norms. They needed to integrate those 
norms into the WTO and its powerful dispute settlement system.

Developing countries could, of course, have proposed revisions to TRIPs without first crafting their proposals in other international venues. Yet their past experience in negotiating in the WTO against more powerful industrialized states made them wary of doing so. In particular, during the Uruguay Round of trade talks leading to the adoption of TRIPs, the United States, European Communities, Japan, and Canada had formed a negotiating "quad" that excluded developing countries from key agenda setting and drafting sessions. As a result of this strategy, developing countries had little choice but to accept the final package deal that the quad presented to them. ${ }^{13}$

The existence of international regimes in which developing countries had greater influence changed the international negotiating dynamic and strengthened their bargaining position in the WTO in two distinct ways. First, the existence of parallel and overlapping venues for intellectual property rulemaking enabled like-minded states to coordinate their challenges to TRIPs around reform proposals that had first been tested and refined in more sympathetic venues such as the CBD, FAO, and WHO. When developing states later introduced these proposals into the WTO (in the second phase of their regime shifting strategy), they followed this previously-agreed-to script for reform. By negotiating as a group to achieve a predetermined outcome, these states created a counterweight to the industrialized country quad. ${ }^{14}$

Second, the existence of parallel and overlapping institutions enabled developing countries to adopt rules in one forum (the CBD, for example) that were in tension with rules previously approved in another venue (such as the WTO). As discussed earlier, these rules decreased the clarity of international law. But they also created "strategic inconsistencies" that developing country officials used to bolster their arguments for revising TRIPs. ${ }^{15}$ In particular, these officials justified their demands for reform by invoking rules endorsed by states, intergovernmental bureaucrats, and legal experts in other international venues. By invoking these previously sanctioned rules, developing states could plausibly claim that their reform proposals were rational efforts to harmonize inconsistent legal rules governing the same subject matter rather than self-serving ploys to back away from a treaty they had previously pledged to uphold. ${ }^{16}$

Developing countries successfully employed this multistep regime shifting strategy to promote the Declaration on the TRIPs Agreement and Public Health, a document adopted by the WTO membership in 2001 as part of the launch of a new round of trade talks in Doha. The Declaration's proponents-a consortium of more than fifty developing states and their NGO allies-demanded greater access to patented medicines used to treat HIV/ AIDS and other pandemics. To support this goal, the coalition relied on proposals to restrict pharmaceutical patents that had previously been adopted in the WHO and the UN human rights system. Developing countries cited these proposals to urge the WTO membership to address "an issue that has aroused public interest and is being actively debated outside this organization, but one which we cannot afford to ignore." ${ }^{17}$ The result was a Declaration that endorsed the coalition's view that TRIPs "can and should be interpreted and implemented in a manner supportive of WTO Members' right to protect public health and, in particular, to promote access to medicines for all." ${ }^{18}$ In the years following the Declaration's adoption, WTO member states have amended TRIPs to expand its compulsory license rules to benefit poor countries facing public health emergencies. ${ }^{19}$

As this discussion illustrates, international regime complexity altered the politics of intellectual property. It allowed developing countries to employ a multi-step regime shifting strategy in which they first created counterregime norms in international venues sympathetic to their interests, and later relied on those norms to enhance their bargaining position in the WTO. Regime complexity thus enabled developing states to increase their power in the WTO in a way that would have been impossible had negotiations been confined to that organization. This mulit-step strategy is only revealed, however, by a dynamic analysis that considers how actors use different international venues of the complex to promote their interests over time.

\section{The Politics of Domestic Implementation of International Rules}

A third consequence of international regime complexity relates to the incorporation of international obligations into national legal systems. As compared to a single-venue regime, the existence of overlapping and parallel regimes modifies implementation politics in two distinct and opposing ways.

First, the multiplicity of legal rules generated in nested, overlapping, and parallel institutions can make it more difficult to claim that states have implemented those rules in ways that violate their treaty obligations. In particular, as the rules regulating intellectual property become more numerous, nuanced, and contradictory, they provide greater leeway for states to interpret and implement rules to further their own interests while remaining nominally within the boundaries of what international law requires.

Decision 486 of the Andean Community provides an apt illustration. Adopted by the biodiversity-rich nations of this South America sub-region in 2000, Decision 486 attempts to reconcile the intellectual property protection rules of TRIPs with the biodiversity preservation measures of the CBD. It does so by imposing various restrictions on patents derived from biological materials found in Andean Community member states. ${ }^{20}$ Whether these restrictions are in fact compatible with TRIPs' patent protection rules 
is open to debate. ${ }^{21}$ Yet no state has filed a WTO dispute settlement complaint challenging Decision 486 as a violation of TRIPs. To the contrary, Andean Countries have promoted the legislation as a good faith attempt to harmonize the two multilateral treaties, albeit an attempt that furthers their own interests in safeguarding the region's biological heritage.

Second, international regime complexity provides opportunities for powerful states to narrow the options available to weaker countries to implement intellectual property rules into their national legal systems. TRIPs expressly contemplates that WTO member states may adopt higher standards of intellectual property protection in other international agreements. Capitalizing on this rule, the United States has sought to strengthen and clarify the obligations in TRIPs via "TRIPs-plus" bilateral treaties. In these negotiations, the United States uses its economic clout to compel weaker developing countries to adopt intellectual property rules that better protect the rights of IP property holders, and that make it less likely that developing countries will invoke the exceptions allowed in parallel multilateral agreements.

For example, TRIPs requires WTO members to protect new plant varieties. But it allows them to do so "either by patents or by an effective sui generis system or by any combination thereof." 22 Developing countries interpreted this provision as permitting them to tailor plant variety protection laws to their domestic agricultural needs. Yet the United States and the European Union have used "TRIPs plus" treaties to restrict this discretion, pressuring several of these countries to enact legislation that favors the interests of foreign commercial plant breeders. ${ }^{23}$

The end result is greater cross-national variation how international agreements are implemented. An analysis of international rules alone may misleadingly suggest greater uniformity than in fact exists. The salient politics emerge only through country-by-country and issue-by-issue interpretations by domestic actors.

\section{Conclusion}

The international intellectual property system is comprised of nested, overlapping, and parallel treaties and institutions that are populated by a shifting mosaic of issues, states, and non-state actors. Scholars seeking to understand the international and domestic politics of intellectual property must consider the ways in which international regime complexity shapes the strategies of state and nonstate actors as they vie for legal and policy dominance over the rules that govern innovation and creativity policies.

\section{Notes}

1 Helfer 2007, 2004a, 2004b.

2 Drahos 2003.

3 Reichman 1995; Sell 2003.
4 Helfer 2004a.

5 Ibid.

6 Alter and Meunier 2009.

7 Drahos 2002.

8 Helfer 2004a, 2004b.

9 GRAIN 2005.

10 Keohane and Nye 2001.

11 Helfer $2004 a$.

12 Helfer 2004c; Saffrin 2002.

13 Drahos 2003.

14 Helfer 2004a.

15 Raustiala and Victor 2004.

16 Helfer 2004a.

17 't Hoen 2002 at 38 n.38.

18 Public Health Declaration 2001, g 4.

19 Abbott 2005.

20 GRAIN 2000.

21 Helfer 2004a.

22 TRIPs, Article 27.3.b.

23 GRAIN 2004

\section{References}

Abbott, Frederick M. 2005. The WTO Medicines Decision: World Pharmaceutical Trade and the Protection of Public Health. American Journal of International Law 99: 317-58.

Agreement on Trade Related Aspects of Intellectual Property Rights (TRIPs). 1994. Marrakesh Agreement Establishing the World Trade Organization, Annex 1C, Legal Instruments-Results of the Uruguay Round Vol. 31; 33 I.L.M. 1197.

Alter, Karen J., and Sophie Meunier. 2009. The politics of international regime complexity. Perspectives on Politics 7 (1): 13-24.

Dinwoodie, Graeme B. 2002. The Architecture of the International Intellectual Property System. ChicagoKent Law Review 77: 993-1014.

Drahos, Peter. 2003. When the Weak Bargain with the Strong: Negotiations in the World Trade Organization. International Negotiation 8 (1): 79-109.

- 2002. Developing Countries and International Intellectual Property Standard-Setting. Journal of World Intellectual Property 5: 765-89.

GRAIN. 2005. Bilateral Agreements Imposing TRIPs-Plus Intellectual Property Rights on Biodiversity in Developing Countries. www.grain.org.

- 2004. Plant Variety Protection (PVP). www.grain. org.

- 2000. Andean Community Adopts New IPR Law. www.grain.org.

Helfer, Laurence R. 2004a. Regime Shifting: The TRIPs Agreement and the New Dynamics of International Intellectual Property Making. Yale Journal of International Law 29: 1-83. 
- 2004b. Mediating Interactions in an Expanding Intellectual Property Regime, Case Western Reserve Journal of International Law 36:123-136.

- 2004c. Intellectual Property Rights in Plant Varieties: International Legal Regimes and Policy Options for National Governments. Rome: FAO.

- 2007. Toward a Human Rights Framework for Intellectual Property. University of California Davis University Law Review 40: 971-1020.

Keohane, Robert O., and Joseph S. Nye, Jr. 2001. The Club Model of Multilateral Cooperation and Problems of Democratic Legitimacy. In Efficiency, Equity, and Legitimacy: The Multilateral Trading System at the Millennium, ed. Roger B. Porter et al. Washington DC: Brookings.

Raustiala, Kal, and David Victor. 2004. The Regime Complex for Plant Genetic Resources. International Organization 58 (2): 277-309.

Reichman, J.H. 1995. Universal Minimum Standards of Intellectual Property Protection under the TRIPs Component of the WTO Agreement. International Lawyer 29: 345-88.
1997. Enforcing the Enforcement Procedures of the TRIPs Agreement, Virginia Journal of International Law 37: 335-56.

Saffrin, Sabrina. 2002. Treaties in Collision? The Biosafety Protocol and the World Trade Organization Agreements. American Journal of International Law 96: 606-28.

Sell, Susan K. 2003. Private Power, Public Law: The Globalization of Intellectual Property Rights. Cambridge: Cambridge University Press.

Steinberg, Richard H. 1997. Trade-Environment Negotiations in the EU, NAFTA, and WTO: Regional Trajectories of Rule Development. American Journal of International Law 91: 231-67.

't Hoen, Ellen. 2002. TRIPs, Pharmaceutical Patents, and Access to Essential Medicines: A Long Way from Seattle to Doha. Chicago Journal of International Law 3: 27-46.

WTO Doha Ministerial Conference, 4th Sess. Nov. 14, 2001. Declaration on the TRIPs Agreement and Public Health, WTO Doc. WT/MIN(01)/DEC/W/2. 